\title{
ESCLAVOS Y CRIADOS: METÁFORAS VISUALES Y MUNDOS IMAGINARIOS
}

\section{SLAVES AND SERVANTS: VISUAL METAPHORS AND IMAGINARY WORLDS}

\author{
Sandra Martínez Rossi \\ Universidad de Málaga
}

\section{RESUMEN}

Los mundos imaginarios vinculados a la representación de la esclavitud exigen una mirada analítica que considere la antropología de la imagen y su semiótica. Los elementos visuales transforman los espacios, las personas y las relaciones sociales y mediante determinados enlaces simbólicos cada personaje se ubica en una zona del cuadro. Criados y esclavos representan desde la metáfora un espacio social liminal mientras que los reyes y nobles asumen el control de la imagen.

La piel como superficie simbólica manifiesta su rango a través del imaginario, una hiperrealidad que exacerba las diferencias entre el ámbito doméstico y/o esclavizante y el hábitat monárquico.

Palabras clave: Imagen, antropología, jerarquía, esclavitud, nobleza.

\section{ABSTRACT}

The imaginary worlds linked to the representation of slavery demand an analytical look that considers the anthropology of the image and its semiotics. The visual elements transform spaces, people and social relationships and through certain symbolic links each character is placed in an area of the painting. Servants and slaves represent from the metaphor a liminal social space while kings and nobles assume the control of the image.

The skin as a symbolic surface manifests its range through the imaginary, a hyperreality that exacerbates the differences between the domestic and / or enslaving environment and the monarchical habitat.

Keywords: Image, anthropology, hierarchy, slavery, nobility. 


\section{RESUM}

\section{ESCLAUS I CRIATS: METÀFORES VISUALS I MONS IMAGINARIS}

Els mons imaginaris vinculats a la representació de l'esclavitud exigeixen una mirada analítica que tinga en consideració l'antropologia de la imatge i la seua semiòtica. Els elements visuals transformen els espais, les persones i les relacions socials, i mitjançant enllaços simbòlics concrets cada personatge s'ubica en una zona del quadre. Criats i esclaus representen des de la metàfora un espai social liminal al mateix temps que els reis i nobles assumeixen el control de la imatge. La pell com superfície simbòlica manifesta el seu rang a través de l'imaginari, una hiperrealitat que exacerba les diferències entre l'àmbit domèstic i/o esclavitzant i l'hàbitat monàrquic.

Paraules clau: Imatge, antropologia, jerarquia, esclavitud, noblesa. 
El presente artículo sustenta su análisis en la antropología de la imagen, es decir, en la interpretación de las representaciones artísticas teniendo en cuenta el contexto sociológico y antropológico en el cual el discurso visual tiene lugar. Esta visión antropológica centra su atención en los sujetos y cómo las imágenes sirven para activar los mecanismos de poder, un particular punto de vista que se aleja del estudio histórico y formal de las obras de arte. Al respecto, de acuerdo con las investigaciones de Hans Belting, nos interesa pensar en términos visuales y no circunscribir el concepto de imagen únicamente al ámbito artístico, en palabras de este autor: "(...) la perspectiva antropológica fija su atención en la praxis de la imagen, lo cual requiere un tratamiento distinto al de las técnicas de la imagen y su historia". ' En relación a las obras artísticas que analizaremos, si bien los elementos iconográficos empleados imprimen a la cultura visual características fijas inherentes a cada época, también funcionan como puntos de inflexión de la semiótica de la imagen y activan en el propio espacio simbólico el tránsito hacia una transformación social de las personas esclavizadas. De este modo, durante este proceso se genera otra imagen la cual, como afirma Hans Belting: "(...) sólo podrá tener el efecto de una nueva porque utiliza un medio nuevo, o porque reacciona a una nueva praxis de la percepción". ${ }^{2}$

En este sentido, los mundos imaginarios se erigen como metáforas visuales del mundo real y en el caso que nos ocupa la representación de la esclavitud exige una mirada analítica que contemple la antropología de la imagen, para ello si bien el objetivo fundamental del análisis es hallar los mensajes ocultos o escamoteados en el seno del discurso visual, resulta imprescindible tener presente que en el ámbito ficcional las diferentes interpretaciones abren un abanico de otros objetivos posibles. Es decir, desde

1 BELTING, Hans (2007), Antropología de la imagen, Katz Editores, Buenos Aires, p. 10.

2 BELTING, Antropología de la imagen, p.69. 
un punto de vista semiótico las imágenes siempre acogen el concepto de metáfora como un medio para explicar -y justificar- los mundos imaginarios que expresan y a través de los cuales se crean las bases simbólicas de las diferentes esferas de la realidad.

Para desplegar esta lectura metafórica establecemos cinco metáforas, por un lado, resulta clave el estudio de los elementos visuales más importantes que se hallan implicados en la composición de las obras analizadas, por otro lado, proponemos analizar cómo la simbología de la mirada implícita en las representaciones pictóricas es dirigida a través de cada recurso compositivo y, por último, creemos relevante puntualizar que el color de la piel es una característica simbólica determinante en el esquema de la composición. De este modo, la primera metáfora se refiere al uso de la luz, la segunda se halla asociada al espacio que ocupa cada personaje en la escena representada, la tercera está en relación a la organización tanto de los elementos iconográficos como de los sujetos protagonistas de la composición y cómo este cambio se verá reflejado en una transformación de los paradigmas sociales, la cuarta está íntimamente ligada a la anterior ya que el análisis detalla el momento en el cual los libertos asumen un rol protagónico tanto en su vida social como artística y, por último, la quinta metáfora visual de alguna manera pretende cerrar el círculo y llegar a una reflexión final que permita abrir el debate sobre la situación de la esclavitud como proyección de una realidad contemporánea.

El punto de partida de este artículo son las representaciones visuales de criados, criadas, esclavos y esclavas en el ámbito europeo durante los siglos XVI y XVII, algunas de estas obras se enmarcan en un periodo significativo de la pintura española, cuando la imágenes renacentistas y religiosas dan paso al Barroco, donde todo fluye y confluye en la luz. El claroscuro, en ocasiones bajo la impronta del tenebrismo, transforma los espacios, las personas representadas y las relaciones sociales entre ellas. Este uso formal y expresivo de la luz enmarcado en esta etapa artística ha sido ampliamente estudiado y no es la intención de este análisis desplegar los conceptos en esa línea, pero sí cabe destacar planteamientos desde otra perspectiva complementaria y no hegemónica que se adecúa más a nuestra propuesta como la idea de "lo barroco" desarrollada por Eugenio y Angel D'Ors o los diferentes ensayos sobre el Barroco escritos por Severo Sarduy que proponen una perspectiva descentrada del Barroco europeo en el contexto sudamericano. ${ }^{3}$ Ambos autores ofrecen una mirada

3 D'ORS, Eugenio y D'ORS, Ángel (2002), Lo barroco, Tecnos, Madrid; y SARDUY, Severo (1987), Ensayos generales sobre el Barroco, FCE, Buenos Aires. 
introspectiva, literaria, filosófica y sociológica del Barroco que excede la época histórica y de cuyos estudios podríamos extraer un cierto carácter antropológico. Estos puntos de vista conectan con nuestro interés en reflexionar sobre el campo lumínico como metáfora de los cambios sociales acontecidos en relación a la esclavitud, y cómo los contrastes de luz son elementos móviles dentro de la representación y proporcionan a las figuras un sentido simbólico específico.

La conexión -o desconexión- visual entre los protagonistas de las obras pictóricas se produce como metáfora de un espacio social liminal, un término utilizado por Arnold Van Gennep y retomado por el antropólogo Victor Turner al referirse a las distintas etapas del proceso ritual, ${ }^{4}$ la fase liminal respondería a ese momento de indeterminación simbólica del sujeto hasta que se consuma la iniciación, un espacio que este autor relaciona con la oscuridad e invisibilidad "estructural" del individuo durante la ceremonia.

La primera metáfora visual que proponemos se ajusta a esta idea, en parte porque el uso de la luz específicamente en las obras pictóricas donde aparecen retratadas personas esclavizadas o sirvientes sirve para reforzar su imperceptible realidad social. En este sentido, en estas representaciones la luz destaca los espacios y provoca intensos contrastes intrínsecamente asociados al color de la piel de cada personaje de la escena, a partir de los matices lumínicos cada uno es ubicado no sólo dentro del espacio pictórico sino que también es "proyectado" al lugar que asume en el estrato social.

De las imágenes se extraen diferentes aspectos que estructuran la composición, en primer lugar, las luces y sombras se utilizan para representar la jerarquía de cada sujeto y en segundo término, gracias a este efecto la figura encarnada en nobles, reyes o reinas adquiere todo el protagonismo. Aquí la reflexión de Severo Sarduy sobre el Barroco aporta una visión muy interesante:

Arte de la argucia: su sintaxis visual está organizada, en función de relaciones inéditas: distorsión e hipérbole de uno de los términos, brusca noche sobre el otro; desnudez, ornamento independiente del cuerpo racional del edificio, adjetivo, adverbio que lo retuerce, voluta: todo artificio posible con tal de argumentar, de presentar autoritariamente, sin vacilaciones, sin matices. Todo por convencer. ${ }^{5}$

4 TURNER, Víctor (1988), El proceso ritual: estructura y antiestructura, Taurus, Madrid, p. 101.

5 SARDUY, Ensayos generales sobre el Barroco, p. 151. 
Un grado de convencimiento que puede advertirse en la mirada de los personajes de la escena cuya proyección organiza la lectura simbólica de la obra, por un lado, los ojos de los esclavos/as o criados/as se hallan intencionalmente dirigidos hacia el interior del espacio representado, al contrario, su amo/a mira hacia el exterior de la representación, es decir, al entorno real. Bajo esta trama, la propia antropología de la imagen está en sintonía con la realidad social, ya que los focos lumínicos y las zonas de penumbra articulan los mundos visibles del cuadro y, en consecuencia, dejan claro desde la metáfora el status social de las personas representadas. En relación al análisis de Victor Turner sobre fase liminal del ritual, ${ }^{6}$ este primer punto establece una conexión visual y simbólica relevante entre la oscuridad del cuadro y la marginalidad e invisibilidad social implícita en la propia condición de esclavitud. Esta asociación simbólica incluso se mantiene fuera del ámbito artístico en la sociedad contemporánea ya que el concepto de "nocturnidad" es atribuido a la juventud cuya vida liminal se mueve en el ámbito nocturno y al margen de la sociedad actual. Según Bárbara Belloc, ${ }^{7}$ estas características se relacionan con un momento de indeterminación, una etapa que atraviesan los jóvenes durante el rito de iniciación a la vida adulta. Traemos a colación esta similitud entre momentos históricos antagónicos en parte porque consideramos oportuno aplicar este estado ritual a los niños y las niñas que aparecen en los retratos de mujeres de la nobleza o realeza, es decir, nos resulta primordial analizar la situación liminal como significante de una parte del proceso de iniciación hacia la propia liberación del esclavo o esclava, un recorrido que en términos artísticos va paulatinamente de la sombra a la luz, pero que a su vez se erige como metáfora de la verdadera transformación social que experimentarán las personas esclavizadas en busca de respeto y reconocimiento. En esta fase liminal, a diferencia de la juventud contemporánea que elige de forma voluntaria el hábitat nocturno para transitar al margen de la sociedad, los esclavos y las esclavas que se retratan en diferentes obras pictóricas de los siglos XVI y XVII se "instalan" involuntariamente a la sombra de su señor o señora.

En esta línea, los sujetos que representan una mayor jerarquía en la sociedad (reyes, reinas, nobles, mercaderes, etc.) suelen emerger en los cuadros como focos de luz en sí mismos, destacando no sólo dentro de la composición sino también evidenciando ese contraste social con sus esclavos/as o

6 TURNER, El proceso ritual: estructura y antiestructura, p. 101.

7 BELLOC, Bárbara (1998), Tribus porteñas, conejillos de indias y blancos ratones: un breviario de zoología urbana, Libros Perfil, Buenos Aires, pp.13-18. 
criados/as a través del color y la luz, incluso en algunos casos, la extrema iluminación les proporciona un halo divino como en las pinturas religiosas de periodos precedentes.

Este grado de jerarquización que la sociedad de la época presentaba en el campo pictórico y especialmente a través de la luz podemos apreciarlo en el Retrato de Laura Dianti realizado por Tiziano aproximadamente entre 1520 y 1525, que actualmente forma parte de la Colección Heinz Kisters. Por aquellos años, casi se podría decir que se había puesto de moda tener como pajes niños o niñas de piel negra, que le otorgaban un aire de exotismo al ambiente aristocrático o monárquico y que eran muy apreciados en las cortes europeas, ${ }^{8}$ una estima que solapaba un interés etnocéntrico por lo exótico. En esta obra vemos a una pequeña niña de tez negra observando a su señora, esta mirada hacia el espacio interior de la representación "retiene" su figura en ese mundo imaginario y, al mismo tiempo, desde la metáfora visual confirma que su existencia "real y simbólica" se halla determinada por su ama. Luce diversos ornamentos y una vestimenta suntuosa, muy característicos de quienes están al servicio de mujeres de alto status social, ${ }^{9}$ detalles que manifiestan notorias diferencias con otras criadas o esclavas, sin embargo, la semejanza del color de la piel con el fondo del cuadro la relega simbólicamente a su condición de servidumbre o esclavitud.

Por otra parte, si tenemos en cuenta que la lectura e interpretación de cualquier imagen se ejecutan desde la zona izquierda de la representación, la ubicación de la niña en la parte lateral, inferior y derecha del cuadro, es decir, en el último punto del recorrido visual, donde la mirada se detiene y la contemplación de la obra concluye, refuerza aún más el lugar social y simbólico de cada una de las figuras. Por un lado, el de inferioridad de la pequeña, ${ }^{10}$ y por otro lado, el de superioridad de Laura Dianti, quien asume el rol protagónico en ambos sentidos, no sólo porque ocupa el espacio central de la composición y su silueta es de mayor tamaño -independientemente de que las medidas de cada personaje estén justificadas por tratarse de un adulto y una niña-, sino también porque mira al espectador, encarnado en el propio artista. Cuando cada observador/a entra a la escena pictórica por el lateral izquierdo se establece un primer contacto visual a

8 LOWE, Kate (2012), "The lives of Africans slaves and people of African descent in Renaissance Europe", en SPICER, Joaneath (ed.), Revealing the african presence in renaissance Europe, Walters Art Museum, Baltimore, p. 17.

9 LOWE, "The lives of Africans slaves", p.20.

10 LOWE, "The lives of Africans slaves", p. 17. 
través del cruce de miradas con la protagonista, que sincrónicamente simboliza una conexión explícita de Laura Dianti con el mundo exterior. Además, el esquema seguido por el artista en cuanto a la ubicación y tamaño de los personajes responde a la jerarquía y subordinación de las figuras protagonistas en las obras renacentistas, sobre todo en aquellas imágenes de carácter religioso.

Una representación similar se puede observar en el cuadro Retrato de Juana de Austria, realizado por el pintor portugués Cristóvão de Morais aproximadamente en el año 1555, durante su estancia como pintor activo de la corte portuguesa entre los años 1551 y 1573, una obra que en la actualidad se encuentra en el Museo Real de Bellas Artes de Bélgica. En esta pintura, como bien afirma Almudena Pérez de Tudela Gabaldón: "(...) existe un marcado contraste entre la perfección real y la imperfección del esclavo", 11 esta oposición potencia la estructura jerárquica y se ve claramente reflejada en el uso de la iluminación como metáfora visual de esa disparidad, el hecho de destacar el rostro y la mano de la protagonista como los únicos puntos de luz y, por lo tanto, de claridad, en contraste con la oscuridad general del cuadro es un recurso que atrapa toda la atención del público.

En cuanto al color de la piel, desde el Renacimiento los tonos claros, la textura tersa y el aspecto luminoso se atribuían a las personas de clase aristocrática o de la realeza, por el contrario, la piel negra se interpretaba como signo de corrupción en relación a la blancura original, ${ }^{12}$ en consecuencia, la piel morena u oscura se erigía como representante de las clases bajas y trabajadoras, cuya tonalidad fue asociada inicialmente al efecto de la exposición prolongada a la luz solar, ${ }^{13}$ en gran parte, esta sobreexposición estaba vinculada a los trabajos agrícolas o de otro tipo realizados en el exterior de los palacios por esclavos/as o criados/as; asimismo, el negro por motivos obvios se relacionaba con el color de la piel de esclavos y esclavas de origen africano. Desde el siglo XV hubo un gran interés por medir la luminosidad de la piel y así, poder establecer desde un punto de vista científico una escala de valores donde la piel blanca ocupaba el primer lugar y la piel negra el último; si bien esta valoración con medios técnicos

11 PÉREZ DE TUDELA GABALDÓN, Almudena (2017), "Esclavos y criados en la corte del rey Felipe II" [ponencia inédita], en Jornadas Internacionales Esclavos y Criados de Nobles y Reyes en España s. XVI y XVII, Palacio de la Madraza, Granada, s. p.

12 MARTíNEZ ROSSI, Sandra (2017), La piel como superficie simbólica. Procesos de transculturación en el arte contemporáneo ( $2^{a}$ ed. actualizada), FCE, Madrid, p. 37.

13 SPICER, Joaneath (2012), "European perceptions of blackness as reflected in the visual arts", en SPICER, Revealing the african presence, p.36. 
recién se pudo llevar a cabo más adelante, indiscutiblemente la creación de estos niveles tenía claras connotaciones racistas. ${ }^{14}$ En definitiva, el personaje "negro" en las obras pictóricas simbolizaba el elemento exótico y, precisamente, el color oscuro de su piel y su mimesis, en algunos casos, con las zonas de oscuridad del cuadro producían un mayor destaque de la "blancura" de su amo, ${ }^{15}$ y por consiguiente, este contraste ponía de manifiesto la condición de superioridad del sujeto blanco y occidental.

Retomando el análisis del retrato de Juana de Austria, podemos decir que se produce el mismo circuito visual a través de las miradas que en el retrato de Laura Dianti y aporta un significado equivalente: el pequeño mira a su señora, estableciéndose un diálogo interno cuya simbología respalda su dependencia social hacia ella y, por otra parte, Juana de Austria mira una vez más al espectador. Con respecto a la ubicación de los personajes, a pesar de que el paje está ubicado a la izquierda y debería ser la primera figura observada, su diminuto tamaño y su camuflaje con el fondo hacen que su silueta sea casi imperceptible y la mirada del observador se posa directamente en los ojos de la protagonista.

En relación a esta obra, Almudena Pérez de Tudela Gabaldón comenta que existía un vínculo fuerte y afectivo entre los pequeños y sus señoras, ${ }^{16}$ y en los cuadros analizados este nexo queda manifiesto por la posición de las manos de las protagonistas, ya que Laura Dianti apoya su mano sobre el hombro de la niña y Juana de Austria la posa sobre la cabeza de su pequeño paje, otorgando, si cabe, un sentido maternal o de protección a la representación. Asimismo, la posición de las manos en actitud de deferencia y cariño continúa apreciándose a finales del XVII en otros retratos similares como el Retrato de Lovise de Kérovaille realizado por Pierre Mignard, y el retrato de Mademoiselle de Blois y Mademoiselle de Nantes realizado por Philippe Vignon. Nuevamente podemos observar la presencia de niños y niñas de origen africano como pajes de aristócratas y reinas, expresión de exotismo que seguía el mismo patrón compositivo: personajes principales jerarquizados y gran contraste lumínico entre las figuras. En el caso del retrato de las hijas de Luis XIV ejecutado por Philippe Vignon, llama la atención de manera sobrecogedora la similitud formal y cromática entre el niño negro y el perrito que sostiene entre sus brazos Mademoiselle de Nantes, ambos destacan por su intensa negrura y su ojos saltones, con un cierto tinte caricaturesco. Dicha asociación se puede interpretar en concordancia

14 MARTÍNEZ ROSSI, La piel como superficie simbólica, p.37.

15 MARTÍNEZ ROSSI, La piel como superficie simbólica, p.43.

16 PÉREZ DE TUDELA GABALDÓN, "Esclavos y criados". 
con el pensamiento de la época, ya que por aquellos años la visión occidental con respecto a los sujetos exóticos venidos de otras tierras estaba ligada al mundo animal y salvaje. Además, resulta sintomático que en la gran mayoría de las pinturas los pajes, criados y criadas representados no se mencionen en el título de la obra, no obstante, la ausencia de esta referencia cambiaría años después.

Los elementos visuales construyen la imagen y la piel se transforma en superficie simbólica, convirtiéndose, una vez más, en testigo de las circunstancias que rodean al imaginario. Como afirma Jean Paul Sartre, el imaginario se halla ligado a la imaginación, que es activada de manera consciente a través de la imagen que como tal es un objeto irreal, sin embargo, este autor afirma: "toda consciencia es consciencia de algo". ${ }^{17} \mathrm{Se}-$ gún Sartre, "cada consciencia postula su objeto", ${ }^{18}$ a sabiendas de que al tratarse de una imagen el objeto-sujeto real no está ahí, pero pese a todo le proporcionamos existencia, queremos creer que es así, aunque sepamos de manera plenamente consciente que no existe. ${ }^{19}$ En este sentido, relacionando esta idea con el análisis visual que se propone en este artículo, las imágenes poseen un significado contradictorio, irónico y poco inocente de la realidad representada, creándose en ellas "una actitud funcional", ${ }^{20}$ es decir, que las representaciones sirven a un cometido específico: ser recreaciones de un determinado contexto real, expresiones de un hipertexto que aumenta las desigualdades entre el ámbito doméstico y/o esclavizante y el hábitat monárquico o noble.

Esta hiperrealidad propone a través de las imágenes ir más allá con el fin de crear otra realidad que enfatice según la mirada de aristócratas y monarcas los aspectos positivos y neutralice los elementos negativos $y$, al mismo tiempo, proponga soluciones desde un punto de vista simbólico a las desigualdades sociales y culturales de la época. Esta estrategia simbólica ha sido utilizada en grupos étnicos sudamericanos como los caduveo y según el análisis de Lévi Strauss la asimetría de los diseños de los tatuajes pretendía equilibrar la división tan marcada de la sociedad caduveo. ${ }^{21}$ En cuanto a las pinturas analizadas y referidas a la esclavitud, la iluminación excesiva en las manos de las mujeres retratadas destacando cualidades

17 SARTRE, Jean Paul (2004), The Imaginary: A Phenomenological Psychology of the Imagination, Routledge, Londres, p. 11.

18 SARTRE, The Imaginary, p. 12.

19 SARTRE, The Imaginary, p. 14.

20 SARTRE, The Imaginary, p. 16.

21 LÉVI-STRAUSS, Claude (1970), Tristes Trópicos, Eudeba, Buenos Aires [citado en MARTíNEZ ROSSI, La piel como superficie simbólica, p.108] 
de empatía y cariño hacia su esclavo o esclava, al igual que su rostro iluminado alegando un halo de santidad podrían interpretarse en la misma dirección, es decir, que la asimetría lumínica manifiesta un mensaje latente en el discurso poético demostrando las bondades de las clases dominantes e intentando generar desde lo simbólico un equilibrio social en el imaginario colectivo. De esta manera, las representaciones pictóricas activan y "justifican" mediante la metáfora visual una vida donde todo encaja y en la cual todo está estrictamente organizado según las convicciones e intenciones de quienes ejercen el poder. En parte, en las obras detalladas esta idealización se manifiesta a partir de una representación quimérica y perfeccionista de la sociedad, que "vuelve a presentar" mediante estos trabajos artísticos otra imagen de la esclavitud. Severo Sarduy se refiere a la concordancia entre el mundo real y el pictórico de una manera muy sugerente:

(...) no se trata de convocar la realidad en el cuadro para, sometiéndola a una iluminación contrastada, brutal, extraer de ella, de su configuración simbólica o de sus referentes mitológicos o bíblicos, una lección, ni tampoco revelar, por medio de la sobre-exposición, el agrandamiento arbitrario o la hipertrofia de un detalle, una verdad moral opuesta a la simulación que el cuadro configura, sino de realizar el cuadro a tal punto que éste se presente, se acredite y justifique como un nuevo fragmento, una nueva porción de la realidad objetiva afirmando así (...) que la supuesta realidad no vale ni más ni menos, que no hay jerarquías, en lo verosímil ni en lo ideológico cuando la ilusión está programada, configurada con el mismo empecinamiento y la misma minuciosidad que la realidad que, en ese grado de reflejo milimétrico, excesivo, ya no la precede. ${ }^{22}$

Esta mímesis simbólica también la observamos en la segunda metáfora visual que está relacionada con el espacio asignado a cada uno de los personajes de las representaciones artísticas objeto de esta reflexión, pero en este caso, la jerarquía no se genera a raíz de la luz sino de las propias fronteras del cuadro, que se reservan para las personas de baja condición social y por tanto, subordinadas a las figuras principales. Esta localización bordeando los límites físicos del bastidor encierra connotaciones simbólicas importantes, pero irá paulatinamente diluyéndose a medida que el su- 
jeto en cuestión vaya experimentando un cambio de estatus. En este punto, por supuesto, resulta esencial citar el estudio de Luis Méndez Rodríguez, quien aplica la idea de borde o margen para referirse al espacio que ocupaban en algunos casos los criados, las criadas, los esclavos y las esclavas en la pintura del siglo de oro, al respecto afirma: "(...) los negros fueron desplazados a los márgenes del lienzo en la pintura europea, teniendo un papel secundario y anecdótico en esta" ${ }^{23}$ Este lugar simbólico se hallaba afín a las circunstancias sociales de aquellos más desfavorecidos, pues como argumenta este autor las clases más bajas y humildes habitaban en la periferia:

Esta situación se agravó en las primeras décadas del siglo XVI, por ordenanzas del Consejo de la ciudad, como la de 1522, que obligó a fijar sus domicilios fuera de las murallas (...) considerando por tanto a los esclavos negros que no convivían todo el tiempo con sus amos y, sobre todo, a los libertos como socialmente peligrosos. ${ }^{24}$

No obstante, el posicionamiento liminal en las obras pictóricas formaba parte de un recurso empleado por el artista para expresar el descentramiento simbólico de criados y criadas con respecto a su señor o señora, pero no siempre esta metáfora visual viene a significar su situación de esclavitud. ${ }^{25}$

De la meticulosa catalogación que llevó a cabo Luis Méndez Rodríguez a lo largo de sus investigaciones podemos extraer que en la producciones artísticas la imagen de los esclavos, especialmente de las mujeres esclavizadas, se vinculó con las tareas domésticas, una actividad común a todas las criadas representadas en los bodegones del siglo XVII. En parte, como bien expone este autor, este condicionamiento se debía al hecho de que muchos artistas compraron a esclavas para realizar estas funciones o adquirían esclavos varones que se dedicaban a limpiar los talleres o a tareas específicamente artísticas y no cualificadas como moler los pigmentos o lavar pinceles. Luis Méndez Rodríguez indica que esta situación se traduciría en la primera "cadena de montaje" de la obra de arte y a la vez en el primer eslabón hacia la especialización de los esclavos en las diferentes disciplinas artísticas, que culminaría con la liberación y profesionalización. ${ }^{26}$

23 MÉNDEZ RODRÍGUEZ, Luis (201 1), Esclavos en la pintura sevillana de los siglos de oro, Universidad de Sevilla, Sevilla, p. 158.

24 MÉNDEZ RODRÍGUEZ, Esclavos en la pintura sevillana, p.37.

25 LOWE, "The lives of Africans slaves", p. 19.

26 MÉNDEZ RODRÍGUEZ, Esclavos en la pintura sevillana, p.68. 
En respuesta a esta tendencia, en la época barroca las representaciones artísticas vinculadas a la esclavitud manifiestan un giro conceptual importante y se perfilan como expresión de la tercera metáfora visual, que expone otra forma de distribución de los elementos visuales dentro de la estructura compositiva. Este reordenamiento da lugar a nuevos parámetros pictóricos y sociales y, al mismo tiempo, saca a la luz un mundo imaginario protagonizado por las esclavas y los esclavos, quienes progresivamente dejan los márgenes del cuadro al desplazarse hacia el espacio central de la composición. Este desplazamiento adquiere un relevante alcance simbólico que más tarde se proyectará en la esfera social como parte del proceso de liberación de varios esclavos y esclavas, al respecto podemos decir que en el espacio pictórico la mirada de estas personas se evidencia mucho más reflexiva y, por tanto, da cuenta de esta inminente transformación.

A partir de aquí, los esquemas binarios: blanco (amo, ama) / negro (esclavo, esclava) y luminosidad (rol protagónico) / oscuridad (rol secundario) caen por su propio peso y las figuras a la "sombra" van ocupando de manera gradual el espacio lumínico, lo cual les permite "dejarse ver" dentro de este nuevo status simbólico. Esta traslación en el mundo del imaginario se posiciona casi inmediatamente en el ámbito real y concreto de una sociedad que ya venía presintiendo ese cambio. Una metamorfosis social de diferenciación que Joaneath Spicer deja bien claro cuando se refiere al hecho predominante de "ser 'no blanco' más que negro per se". ${ }^{27}$ En un cierto sentido, las imágenes sobre la esclavitud están estrechamente ligadas a las representaciones raciales, como bien afirma Alessandra Raengo, cumplen una función ontológica, ser precisas como el reflejo de un espejo y confiables como una sombra, sin embargo, esta confianza se ve socavada cuando la imagen especular representa el encuentro del sujeto blanco y occidental con el Otro, algo sesgado y opaco que se debe rechazar. ${ }^{28}$ Cabe puntualizar, que mientras el Otro permanecía a la sombra como metáfora visual de subordinación y esclavitud, quien ejercía el poder tenía plena certeza de tener ambos mundos -real e imaginario- bajo control, no obstante, el avance simbólico de esclavos, esclavas, criados o criadas hacia el centro de la escena pictórica manifiesta en todas las esferas una inquietante desestabilización, paradójicamente expresada a través de la mirada del propio artista.

Un ejemplo de esta evolución podemos encontrarlo en la criada retratada por Velázquez, a este respecto Luis Méndez Rodríguez comenta que

27 SPICER, "European perceptions of blackness", p.40.

28 RAENGO, Alessandra (2013), On the Sleeve of the Visual: Race as Face Value, Dartmouth College Press, New Hampshire, p. 132. 
se trataba de una temática poco común en la pintura hispalense. ${ }^{29} \mathrm{Se}$ le atribuyen a Velázquez dos versiones de esta obra, por un lado, Criada de cocina con la cena de Emaús (1617-1618), ${ }^{30}$ en esta pintura que se encuentra en la Galería Nacional de Irlanda en Dublín se aprecia en el fondo del cuadro la escena de Cristo en Emaús, pero del relato bíblico tan sólo aparece un fragmento, el cual fue descubierto tras una restauración en 1933 y en su momento hubo un intenso debate sobre la autoría del artista en este detalle. ${ }^{31}$ Por otro lado, la obra Escena de cocina (1618-1620), ${ }^{32}$ que forma parte de la colección del Instituto de Arte de Chicago, representa exclusivamente a la mulata en la cocina sin la escena religiosa.

La inclusión de la parte bíblica en esta obra de Velázquez se interpretó como un "bodegón a lo divino", 33 además, la presencia del fragmento de la cena de Emaús se ha asociado al cuadro Los discípulos de Emaús o Cena de Emaús pintado por Caravaggio en 1602 (del cual también existe una segunda versión de 1606) y aparte de que ambas pinturas comparten el mismo pasaje de la Biblia, también aparecen sirvientes representados en ellas; equivalencia que puede apoyarse en el hecho de que la primera época pictórica de Velázquez tuvo influencias del artista italiano. En la obra de Caravaggio podemos observar que el criado mantiene una actitud impasible ante la presencia de Cristo, al contrario, en el cuadro de Velázquez, la inclinación leve de la cabeza de la criada podría manifestar humildad y devoción, igualmente, cabe destacar que Velázquez ubica a la criada en el mismo lugar central asignado a Cristo por Caravaggio, lo cual le proporciona a la sirvienta un gran protagonismo y relega la escena bíblica a un segundo plano dentro del esquema compositivo. Además, el rol protagónico de la criada se acentúa debido al mayor contraste lumínico de la representación que destaca su rostro y al detalle de los utensilios mediante una gran riqueza de matices cromáticos que le otorgan a las tareas domésticas un halo mágico y místico a la vez.

29 MÉNDEZ RODRÍGUEZ, Esclavos en la pintura sevillana, p. 75.

30 En exposiciones monográficas como Velázquez a Capodimonte realizada en el Museo di Capodimonte de Nápoles en el año 2005, este cuadro se presentó bajo el título Cena de Emaús obviando la primera parte referida a la criada.

31 LÓPEZ-REY, José (1996). Velázquez. Catalogue raisonné, vol. II, Colonia, Taschen Wildenstein Institute, p.42.

32 En la colección del Instituto de Arte de Chicago figura con el título Escena de cocina sin hacer mención a La mulata, título con el que se suele conocer comúnmente esta obra, aunque otras veces se utilizan los dos conjuntamente.

33 GÁlLEGO, Julián (1988), Diego Velázquez, Anthropos, Barcelona, p. 42. 
Por otro lado, a este cambio simbólico en las composiciones pictóricas debemos sumar un detalle importante en relación a la mirada de las personas de origen africano retratadas con gran virtuosismo a finales del siglo XVI durante el Renacimiento tardío, un posicionamiento frontal de la mirada que ponía de manifiesto metafóricamente los cambios sociales que se avecinaban. Tal es el caso de la obra Retrato de una mujer esclava africana (fragmento de un cuadro de mayor tamaño que incluía a su señora), atribuido a Annibale Carraci hacia el año 1580 y que perteneció a la Colección de Felipe V. Asimismo, este cuadro formó parte de la exposición Revealing the african presence in renaissance europe presentada en el Walters Art Museum (octubre 2012 - enero 2013) y en Princenton University Art Museum (febrero - junio 2013). Según los comisarios resultaba esencial el reconocimiento de la existencia de los esclavos y las esclavas en la pintura renacentista, de alguna manera, a través de esta exhibición se les daba visibilidad como una forma de restituirles su identidad. ${ }^{34}$ Desde la intrínseca antropología de la imagen se puede discernir cómo en el cuadro mencionado la protagonista mira directamente hacia el exterior de la representación, una acción que atrae y "atrapa" al público hacia el interior de la composición. Esta inversión del juego de miradas expresa una gran originalidad y un avance simbólico importante con respecto a los retratos reseñados, ya que en este trabajo en particular la esclava ejerce un rol activo al proyectarse fuera del lienzo y mediante esta actitud, simbólicamente expulsarse de ese mundo imaginario que la confina a la esclavitud.

En consecuencia, tanto la reubicación espacial en el esquema compositivo como la inversión del acto de mirar de las personas esclavizadas van a anticipar desde el ámbito simbólico la transformación social y artística protagonizada por esclavos o esclavas a partir del siglo XVII.

Esta anticipación simbólica da pie a la cuarta metáfora visual, que se enmarca en el cambio significativo llevado a cabo durante la primera mitad del siglo XVII por algunos esclavos quienes tras convertirse en libertos al obtener la liberación por parte de sus amos se dedican al trabajo artístico y a partir de aquí asumen el control de su vida y el de la representación pictórica. El caso más famoso fue el de Juan de Pareja, esclavo de Velázquez, quien fuera retratado por su amo en 1650 durante una estancia del artista en Roma y que ese mismo año recibe la carta de libertad..$^{35}$ El retrato

34 GARY, Vikan, "Director's foreword", en SPICER, Revealing the african presence, p. 7.

35 Sobre diferentes aspectos de la vida y obra de Velázquez consultar: BROWN, Jonathan (2008), Escritos completos sobre Velázquez, Centro de Estudios Europa Hispánica, Madrid. Desde una narrativa histórica resulta muy interesante VILLAVERDE, Fernando (2014), El esclavo de Velázquez, Suma, Barcelona. 
de Juan de Pareja, que actualmente se conserva en el Museo Metropolitano de Nueva York, fue realizado cuando aún él era esclavo, por ello, su figura todavía mantiene una cierta similitud cromática con el fondo del cuadro y, al igual que sucede en otras obras, este recurso le impide "despegarse" de la representación en un doble sentido: simbólico y social. En otras palabras, una vez más la innata antropología de la imagen manifiesta que el esclavo todavía preserva el rol de dependencia social hacia su amo y sigue "fijado" al mundo del imaginario hasta que se haga efectiva su liberación en 1654. Pese a ello, la imagen es realmente impactante, el esclavo luciendo un elegante vestuario adquiere una postura levemente inclinada, pero que denota cierta seguridad; con su cabeza en alto -al contrario que la criada retratada por Velázquez 30 años antes- y su mirada un tanto altiva transforma literalmente la semiótica de la imagen. A partir de esta nueva perspectiva, el simple acto, pero al mismo tiempo trascendente, de elevar la cabeza y mirar de frente, presagia el surgimiento de un nuevo ser que se está gestando en su interior, la creación de otra identidad que dejará atrás al esclavo para dar paso a Juan de Pareja, el artista.

Resulta paradójico que poco más de una década después, en 1661, Juan de Pareja realizaría un remake de ese retrato en su obra Conversión de San Mateo, la cual se puede contemplar en la actualidad en el Museo del Prado. Sobre este autorretrato Luis Méndez Rodríguez señala: "(...) se ha difuminado su fisonomía intencionadamente para ofrecer un aspecto diríamos más occidental. En su recién adquirido honor social, se libera de su condición de esclavo y de sus rasgos morfológicos de mulato", ${ }^{36}$ e incluso podemos intuir un parecido físico con el propio Velázquez.

La quinta y última metáfora visual que desarrollaremos está íntimamente asociada al retrato de Juan de Pareja realizado por Velázquez y su inserción en el ámbito artístico actual, esta extrapolación a la contemporaneidad nos permite abordar las reflexiones finales de un modo circular $y$, en cierto modo, concebir las distintas metáforas como puntos hacia una meta común al ver cómo artistas contemporáneos reciben el testigo de una realidad tan dramática como la esclavitud y reabren el debate mediante un discurso poético, crítico y reflexivo.

El artista senegalés Omar Victor Diop ejecuta en palabras de David Le Bretón una "citación cultural", ${ }^{37}$ mediante una personal apropiación simbólica

36 MÉNDEZ RODRÍGUEZ, Esclavos en la pintura sevillana, p. 147.

37 LE BRETON, David (2002), Signes d'identité. Tatouages, piercings et autres marques corporelles, Métailié, París, p. 161. 
recrea autorretratos de hombres ilustres de origen africano, que en su mayoría fueron esclavos o hijos de padres esclavos o libertos y que formaron parte de la historia europea entre los siglos XV y XIX, según la opinión del propio artista se trata de un período de intensa interacción entre África y el resto del mundo. ${ }^{38} \mathrm{~A}$ través de la fotografía propone su particular versión en un intento por reivindicar la dignidad de cada uno de los personajes retratados, una serie fotográfica que integra el proyecto expositivo Diáspora, presentado en el Gran Palais de París en el año 2014.

Este proyecto surge a raíz de una residencia artística de cuatro meses en la ciudad de Málaga, donde el artista inició una investigación acerca del sentimiento de ser "otro", de ser extranjero, centrando toda su atención en "(...) la dualidad de vivir una vida de gloria y reconocimiento frente a los desafíos de ser otro", ${ }^{39}$ una paradoja que él observa entre los futbolistas africanos que juegan en equipos europeos y los personajes de retratos antiguos que él decide imitar a través de la fotografía. ${ }^{40}$ Esta alusión al fútbol en las imágenes se produce mediante la incorporación de diferentes objetos del ámbito futbolístico como trofeos, balones o botines y también por la representación de figuras claves de este deporte como los árbitros.

Entre las obras pictóricas originales seleccionadas por Omar Victor Diop se encuentra el retrato de Juan de Pareja realizado por Velázquez, pero en esta versión contemporánea, el artista no sólo asume la personalidad del esclavo sino que la representación expresa algunas modificaciones que transforman el sentido original.

En esta obra el artista nos mira de una forma más frontal y desafiante, no disimula el color de su piel como lo hizo Juan de Pareja al retratarse en la Conversión de San Mateo y, además, en esta imagen contemporánea el retratado se separa completamente del fondo de la composición, un recurso que desde un punto de vista simbólico "trae al frente" al esclavo, de tal modo que en la fotografía el color de la piel resalta de manera contundente y el personaje ya no se difumina en la sombra. En este sentido, de la propia antropología de la imagen podemos percibir que el contraste de luz y color le confiere al sujeto relieve y volumen, con la clara intención de avanzar hacia el exterior de la representación y con el fin de plantar cara a la sociedad, un acto que sin lugar a dudas dignifica desde la metáfora al olvidado Juan de Pareja.

38 WILSON, Raquel, "Diáspora. Self-portrait, 2014", s. p.

[Recuperado de: https://www.omarviktor.com/project-diaspora]

39 WILSON, "Diáspora", s. p.

40 WILSON, "Diáspora", s. p. 




Fig. 1. Omar Victor Diop. Juan de Pareja, 2014. Diaspora series. (C) Omar Victor Diop. Courtesy Galerie MAGNIN-A, Paris. 
Omar Victor Diop caracterizado en la figura del esclavo sostiene unos botines de fútbol, que le otorgan a la imagen un aire de extrañeza, incluso rozando el absurdo si tomamos como referencia la pintura original; sin embargo, como ya hemos señalado, con esta inclusión iconográfica el artista senegalés pretende actualizar y enunciar a través de este tipo de objetos la realidad que comparten tanto los hombres ilustres retratados como los futbolistas africanos actuales, y que pese a los siglos que los separan, ambos colectivos han sido víctimas o aún siguen sufriendo las mismas circunstancias: fama y otredad.

Mediante esta serie fotográfica Omar Victor Diop pretende cuestionar la propia construcción de la historia y, simultáneamente, dar respuesta a sus propios interrogantes acerca de su identidad como artista y como persona. ${ }^{41}$ Esta última metáfora visual planteada en el contexto del mundo artístico contemporáneo establece lazos con el pasado y evidentemente desvela de forma clara el objetivo principal de este artículo, ya que revela que tanto los elementos iconográficos como los mensajes latentes que subyacen en el seno de las composiciones artísticas expresan aspectos específicos del entramado social. Por otra parte, el proyecto Diáspora presentado por Omar Victor Diop completa el análisis al expresar los vaivenes históricos y poner a debate las vicisitudes del mundo "real" e "imaginario" entre África y Europa. En definitiva, hemos llegado a un punto del recorrido donde todo parece confluir en otra visión de la sociedad y de la historia, donde finalmente y sin reparos podemos afirmar: "Black is beautiful". ${ }^{42}$

41 WILSON, "Diáspora", s. p.

42 "Black is beautiful" fue un movimiento cultural norteamericano surgido en 1960 que luchaba por los derechos de las personas de origen africano en contra de argumentos raciales y estereotipos de belleza basados en la estética blanca y occidental. También nuestra cita se refiere a la exposición Black is beautiful: from Rubens to Dumas, que se llevó a cabo del 26 de julio al 26 de octubre de 2008 en De Nieuwe Kerk, Amsterdam. Esta exhibición proponía un extenso recorrido sobre la representación de personas de piel negra en la pintura de los países bajos desde el siglo XIV hasta la actualidad, cuyo título cita -a modo de homenaje- aquellas reivindicaciones iniciadas hace casi 60 años. 